FILOLOGÍA INGLESA 



\title{
MAIN VERB+GERUND CONSTRUCTIONS IN ENGLISH EXPLAINED BY MEANS OF SEMANTIC TRANSITIVE FEATURES
}

\author{
M. ángeles Gómez Castejón \\ Catholic University of Leuven (K. U. Leuven, Belgium)/UNED \\ angeles.gomezcastejon@hotmail.com
}

\section{Abstract}

There have been remarkable works on semantic transitivity although they are, to a certain extent, limited. Firstly, most of these works have only focused on syntactic constructions in which the second participant, syntactic direct object, is a Noun Phrase. Secondly, most of the works dealing with gerunds as syntactic direct objects, do not take semantic transitivity into consideration. We claim that gerund complements occurring after main verbs (i.e. [subject] [main verb] [gerund]) can be explained by taking the notion of semantic transitivity as a reference. In this sense, semantic transitivity is based on features relevant to two-participant events. In this context, a prototypical transitive event implies an event instigated by a volitionally acting agent that causes a change in an affected patient. Therefore, with the aid of a corpus, we aim to analyse the structure [subject] [main verb] [gerund] in English in relation to the most relevant features involved in coding semantic transitivity, in particular, in terms of the prototypical agent and patient.

KEY WORDS: semantic transitivity; structure [subject] [main verb] [gerund]; twoparticipant events; prototypical agent and patient

\section{RESUMEN}

Ha habido trabajos destacados sobre la transitividad semántica a pesar de que presentan ciertas limitaciones. En primer lugar, la mayoría de estos trabajos se han 
centrado sólo en construcciones sintácticas en las que el segundo participante, objeto directo, es un sintagma nominal. En segundo lugar, la mayoría de los trabajos que se ocupan de los gerundios como objetos directos, no toman en cuenta la transitividad semántica. Afirmamos que los gerundios en función de complemento que aparecen después de los verbos principales (es decir, [sujeto] [verbo principal] [gerundio]) pueden explicarse tomando el concepto de transitividad semántica como referencia. En este sentido, la transitividad semántica se basa en las características relevantes que describen los eventos de dos participantes. En este contexto, un evento transitivo prototípico implica un evento instigado por un agente volitivo que causa un cambio en un paciente afectado. Por lo tanto, con la ayuda de un corpus, nos proponemos analizar la estructura [sujeto] [verbo principal] [gerundio] en inglés en relación con las características más relevantes que intervienen en la codificación de la transitividad semántica, en particular, en términos del agente y paciente prototípico.

Palabras Clave: transitividad semántica, estructura [sujeto] [verbo principal] [gerundio]; eventos de dos participantes; agente y paciente prototípico

\section{INTRODUCTION}

Recent studies on transitivity provide a complex approach of the term Transitivity, but at the same time this term has become quite vague (e.g. Kittilä, 2002, 2006; Naess, 2007). In fact, its definition in terms of the number of core arguments has limited usefulness from a practical point of view, given the great number of cases which fall into this category. Nevertheless, it provides a clear understanding of what is meant by this term: the transitivity of a verb refers to its ability to occur with more than one core argument.

According to Hopper and Thompson (1980: 251), transitivity is generally interpreted as a global property of an entire clause, whereby an activity is «carried-out» or «transferred» from an agent to a patient. Transitivity implies at least two participants and an action which is typically effective (Hopper and Thompson, 1980: 251). Transitivity is thus understood as a matter of transferring an action from one participant to another which is made up of different components, each aiming at a different aspect of this transfer of energy (Hopper and Thompson, 1980: 253).

Therefore, a fully transitive event has one Initiator which instigates the event and one Endpoint which reveals the effect of the event. According to Kemmer (1993), it is a basic requirement that the Initiator and Endpoint participants should be two physically distinct entities and that the event should entail some kind of transmission of force from the Initiator to the Endpoint participant. He specifies that the initiating entity should be human and act volitionally; whereas the Endpoint, a patient, should be inanimate, definite and completely affected by the event instigated by the agent.

In the same line of thought, Kittilä (2002: 128) defines the prototype of a transitive event as a single, concrete and dynamic event in which a volitionally acting definite and referential agent acts on a definite and referential patient that is not co-referential with the agent and which is directly affected by the action in a perceptible manner. 
Taking into account all the previous observations, it seems that humanness and definiteness of arguments are considered as an integral part of the transitivity of events. These kinds of formulation are motivated by the fact that a basic two-actant sentence implies human or otherwise highly definite entities. In other words, there must be a physical and conceptual distinctness of the two participants in the event (Kemmer, 1993).

Nevertheless, according to Kittilä (2002), the definiteness of arguments does not contribute to the semantic definitions of a prototypical event because it is only associated with the conceptualizations of the participants. The contrast between two highly individuated participants is irrelevant to determine the transitive prototype. The relevance lies at a completely different level of analysis: the contrast between the semantic roles, agent and patient, involved in a transitive event (Næss, 2007; Kittilä, 2002). In conclusion, prototypical transitivity is defined as a maximal opposition between agent and patient. In other words, a canonical transitive event involves the semantic roles, agent and patient, which must be maximally distinct (Næss, 2007).

From our point of view, transitivity in the twenty-first century is a complex notion which relates to a number of different properties. The term of transitivity must then be interpreted as a cluster of different properties some related to core arguments, some to verbal semantics, some to grammatical operators at clause level (Naess, 2007: 85). For this study we will mainly focus on the core arguments and verbal semantics, because by means of these properties all the other transitivity features can be better explained and understood.

Since the above observations have been made for syntactic constructions in which the second participant is a Noun Phrase, one might ask whether the gerund complements in the composite structure [subject] [main verb] [gerund] can be explained fully and adequately in terms of semantic transitivity as described above. And in particular if this composite structure includes as core arguments the prototypical agent and patient.

With the support of a corpus ${ }^{1}$, in this paper we intend to analyse the structure [subject] [main verb] [gerund] in relation to the most relevant features involved in coding semantic transitivity. This analysis helps us, on the one hand, to determine the differences between this structure and the prototypical transitive clause, and, on the other hand, this enables us to describe this structure according to its own specific features (Langacker, 2000, 2008; Radden and Dirven, 2007). Although, our analysis is methodologically corpus-based, we aim to conduct a qualitative study. We will provide percentages for informative purposes only. All examples provided can be found in our corpus, in which the source texts are provided in brackets. A specific code has been used in which the first letters make reference to the title of the source text, and the numbers refer to the order within the corpus.

In order to achieve our objective, the outline of this paper is as follows. In section 2, we will present the main features of the prototypical transitivity. In section 3, we will present the results and discussion. We will analyse all the individual transitivity features in relation to the structure [subject] [main verb] [gerund]; in particular, the subject participant (3.1.), the verbal semantics (3.2.) and the object of these constructions, i.e. the gerund (3.3.). And finally, we will provide some concluding remarks in section 4 . 


\section{Prototypical transitivity}

There have been remarkable works on semantic transitivity and although they differ from each other, they converge on essentially the same semantic properties: a volitional agent, an affected object and a dynamic action (Hopper and Thompson, 1980; Givón, 2001; Kittilä, 2002; Naess, 2007). At this stage, it seems necessary to describe the nature of these participants.

First of all, there has been a traditional opposition between agent/subject and patient/ object in terms of definiteness and animacy (Naess, 2007: 30). Noun Phrases (henceforth, NPs) in subject postion are mainly definite and animate, and it is asserted that it is most natural for objects to be indefinite and inanimate (Naess, 2007: 30). But we know that definiteness and animacy are properties of NPs and their referents, despite their function in the clause. The correlation between these properties and the natural tendency of participants is obvious: animate participants tend to be involved in active participation, agency; whereas inanimate participants are inherently more likely to be patients.

Nevertherless, the meaning encoded in a prototypical transitive clause entails two arguments, agent and patient participants. Definiteness and animacy are inherent properties, agency, whereas patienthood is considered a relational property. Assuming an opposition in transitive clauses based on relational properties (i.e. a maximum contrast between an active and a passsive participant) does not imply a corresponding contrast in the inherent properties of the NP representing the arguments in question (Naess, 2007: 31). According to Naess, the notion of distinguishability of participants, although important, is not the relevant issue to determine the transitive prototype, what seems to be relevant is the contrast between the semantic roles, agent and patient, involved in a transitive event (2007: 36).

The terms agent and patient, to be defined below, refer to participant roles rather than thematic roles (Naess, 2007: 36). In that way, an agent is a participant having certain properties in a given instance of acting independently of any semantic properties imposed by the verb, in contrast with thematic roles that are assigned by verbs to their arguments.

The definitions of the categories agent and patient should be based on properties related to the encoding of two-participant clauses. These properties can be of two types: inherent properties of the NP or NP referent, and relational properties, that is to say, the properties defining the relation of the participants to the event. Agent and patient participants are understood as participant roles and therefore the inherent properties are not directly relevant to their definition, except they may restrict the type of relational properties a given participant may show.

According to Naess (2007: 42) the semantic relation agent can be defined in terms of volitionality and instigation. Firstly, volitionality should be understood as a relational property, «that is the volitional involvement of a participant in a given instance of acting» (Naess, 2007: 42). The term volitionality will be used here in the sense of the precise nature of the participant's involvement in the event by its being volitional or sentient. Volitionality also refers to the situation whereby a participant involves its cognitive capacity in interacting with an event. Secondly, the property of instigating or causing an event is central to the definition of an agent. The fact that the agent participant instigates 
an event is highly relevant in the encoding of two-participant events (Naess, 2007: 42) and it implies an act where one participant «does something to» another.

As far as the notion of patient is concerned, the main property is that of affectedness. A patient is generally defined as the participant that undergoes a change of state as a result of the event (Naess, 2007: 42). The affectedness of the patient is a direct result of the event instigated by the agent and is the target of the agent's volitional act.

Taking into account the properties discussed above, volitionality, instigation and affectedness, an agent participant will be defined as being + Volitional or [+VOL] and + Instigating or [+INST], whereas the patient is defined as +Affected or [+AFF]. So to provide the whole picture, an agent participant will be [+VOL], [+INST] and [-AFF] and a patient participant will be [-VOL], [-INST] and [+AFF]. Although we rely on the theoretical framework of Naess to carry out our analysis, we would like to point out that there have been other linguists who have worked on this particular issue with relevant contributions such as Kitilä (2002, 2006) and Hopper and Thompson (1980), among other scholars.

To conclude this section, we would like to point out again that there is a general agreement on the essential features of the transitive prototype (i.e. a volitionally acting agent participant performing a concrete, dynamic action on a perceptible concrete, affected patient). In this sense, we fully agree with Naess that transitivity must be defined as a maximal opposition between the semantic roles, agent and patient. In other words, a prototypical transtitive event entails a prototypical agent and a prototypical patient, neither of which shares any of the defining properties of the other. On the other hand, the prototypical event should be presented as real and concluded. To put it another way, the clause should show perfective rather than imperfective aspect, realis rather than irrealis mood, be positive rather than negated (Naess, 2007: 15). The properties of the events are not discussed in detail in this article as they can be somehow deduced from the analysis of the core participants and verbal semantics.

\section{RESUltS AND DISCUSSION}

As pointed out above, the semantic transitivity of prototypical transitive clauses has attracted much attention for decades. In contrast, no attention has been paid so far to how the structure [subject] [main verb] [gerund] can be analysed in terms of the prototypical transitivity. In this section, we will study this structure in relation to the following semantic features: the subject participant (3.1.), verbal semantics (3.2.) and, finally, the object (i.e. the gerund) (3.3.).

\subsection{Subject participant}

Our purpose in this subsection is to analyse what kind of subject participant is present in the structure [subject] [main verb] [gerund]. Since the prototypical event only includes the prototypical agent for the subject participant, any variation in this regard would confirm that this structure is far from being prototypical. 
Agent [+VOL, +INST, $-A F F]$

Agents, defined as being + Volitional [+VOL], +Instigating or [+INST] and non Affected or [-AFF], represent half of the instances analysed in terms of frequency (i.e. $51 \%$ ). The agent role shows the properties central to the definition of the semantic role of agent; that is to say, the subject participant shows an intentional and conscious involvement in relation to the event:

(1) a. They started building at each end of the site, Arts at one end and Sciences at the other, confident that they would soon fill up the intervening acres. (THIN 71) b. On just my previous visit, Coleman had begun waving something in my face from the moment I'd come through the door, yet another document from the hundreds of documents filed in the boxes labeled «Spooks.» (HUM 5)

But one may ask whether this agent participant is prototypical in the terms explained in section 2. We can assert that the agent, in the constructions above, combined mainly with aspectual verbs (91\%), is not the prototypical agent who «does something to another»; or in other words, it is not involved in a concrete, dynamic event.

However, the composite structure [agent] [aspectual verbs] [gerund] can evoke, in some particular aspects, a transitive event. In the majority of the cases, the events are perfective vs imperfective aspect (e.g. use of simple tenses, mainly simple past), realis vs irrealis mood (e.g. use of indicative mood), positive vs negated (e.g. afirmative sentences), so they should be considered real and concluded events (Næss, 2007: 15). In fact, the context provides an observable confirmation of the event being completed and real such as in (1a) the fact of starting the building of the universities is proved: «Arts at one end and Sciences at the other» or in (1b) the fact of waving something in my face is corroborated by providing the exact nature of this «something» waved: «another document from the hundreds of documents filed in the boxes labeled». This «observable confirmation of the events» seems to bear some resemblance to the «perceptible affectedness of the patient» characteristic of semantic transitivity as already presented in section 2 .

Within the instances related to the agent role, we find instances that should be interpreted as metaphoric extensions of the semantic relation «agent» (Givón, 1980: 128). There are inanimate and non-human entities playing the semantic role of agent. Or in other words, these entities display human or animate qualities and behavior, and they act deliberately to initiate the event, for example «articles appear» and «birds comment» in (2a) and (2b) respectively:

(2) a. When Colin first went to St Joseph's after his not very good comprehensive, articles she knew were not his began appearing, nothing much, a T-shirt, packets of biros, a record. (SWEE 106)

b. Sarah walked about in the dusk for a while, until the birds stopped commenting on the affairs of the day and the moon made itself brilliantly felt. (LOVE 152)

As already mentioned, a prototypical transtitive event entails a prototypical agent for the subject participant, thereby if a construction has different participant types other than the agent participant, this construction is not fully transitive lexically. In fact, the 
structure [subject] [main verb] [gerund] presents a greater variety of participant types, apart from the agent one; in particular, those of experiencer, force, frustrative, hypothetical agent and hypothetical experiencer. In this sense, the feature-based definition of the agent and patient categories provided in section 2 represents the basic defining property of a transitive event, all other distribution of these semantic features entails other participant types. To this end, each of «the other participant types» will be defined according to the semantic features of volitionality, instigation and affectedness, and the configuration of their values (i.e. +/-) as being [+/-Volitional] or [+/-VOL], [+/-Instigating] or [+/-INST] and [+/-Affected] or [+/-AFF] respectively. «The other participant types» included are the types of experiencer, forces, frustrative analysed according Naess' description (2007: 89-102), in contrast the types hypothetical agent and hypothetical experiencer must be considered our own contribution to this particular part of the work.

Experiencer $[+V O L,-I N S T,+A F F]$

Experiencers are defined as being + Volitional or [+VOL], non Instigating or [-INST] and +Affected or [+AFF] and represent one third of all the cases (29\%). In terms of volition, experiencers are volitionally involved in the sense that their mental or sensory capacities are engaged in the event (Naess, 2007: 90). They are defined as participants who are animate and affected; the type of affectedness registered with experiencers is that of experiencing a sensory impression, or a mental or physical state (Naess, 2007: 91).

From our data, we corroborate that there is a high frequency of experiencers combined with emotion verbs in these constructions (72\%) followed by cognitive perception verbs $(20 \%)$ as seen in $(3 a)$ and $(3 b)$ respectively:

(3) a. Indecency? Who knows? Do as you like, Sabbath said, and she did and liked it and liked telling him about how much she had liked it no less than he liked hearing about it. (SAB 9)

b. Sometimes he imagines a beautiful girl in a white dress wandering into the reading room and lingering distractedly after closing time; he imagines showing her over the mysteries of the bindery and cataloguing room, then emerging with her into the starry night. It never happens. (YOU 41)

Forces $[-V O L,+I N S T,-A F F]$

Forces are described as non Volitional or [-VOL], +Instigating or [+INST] and non Affected or $[-\mathrm{AFF}]$ and occur rather infrequently in our database $(8 \%)$. These participant types employ their own energy in carrying out an action (Cruse, 1973; Croft and Cruse, 2004) but they deviate from the traditional definition of agent in that they are not volitionally involved in the action and therefore the result is not intentional, that's what Kittilä (2002) terms «Involuntary Agent Events».

In fact, in our corpus we have mainly found self-driven forces with no capacity for volitional action and mainly combined with causal verbs (i.e. bring and entail) (Naess, 2007: 93). For example, the verb entail is particularly illustrative and interesting in these examples as its semantic nature explains its presence with this type of participant. Just 
to remind ourselves, the verb entail means «to make something necessary as a means or result of getting something else». In (4a) and (4b), entail implies to do something, «going to bed with him», as the first step to getting something else, «haranguing him about» respectively:

(4) a. She has come, she says, not to resume residence with him ('You are impossible to live with') but to patch up a peace ('I don't like bad blood, it depresses me'), a peace that entails first going to bed with him, then, in bed, haranguing him about what he said about her in his diary. (YOU 44)

b. She has come, she says, not to resume residence with him ('You are impossible to live with') but to patch up a peace ('I don't like bad blood, it depresses me'), a peace that entails first going to bed with him, then, in bed, haranguing him about what he said about her in his diary. (YOU 45)

Frustrative [+VOL, $-I N S T,-A F F]$

Frustrative participants, characterised as +Volitional or [+VOL], non Instigating or [-INST] and non Affected or [-AFF], show a low frequency (5\%). Frustratives are defined as participants which are volitionally involved in some state of affairs but do not instigate anything either because they are unable to or are prevented from carrying out the act, they could be regarded as «non-doing» participants (Naess, 2007: 93).

In most of the cases, frustrative participants are the result of the presence of negation. In other words, the presence of «not» in the main verbs «haven't got round to» and «had not finished» implies that the actions «going through this» (i.e. your old school reports) or «cleaning» have not finally been completed:

(5) a. I haven't got round to going through this. Your old school reports, believe it or not. I thought you might want to keep them. He held up papers. (NONE 58) b. For one thing, she had not finished cleaning until there in the morning. Then she decided to do the programme notes after all. Then she reread Julie's journals, preparing herself for what she believed would be a fight with Julie's Angel. (LOVE 118)

We would like to point out that there are certain grammatical operators that function as «feature-switchers»; that is to say, they change the value of centain features of the arguments of the clause. In this context, negation can be conceived as a «feature-switcher», because under negation, the subject argument can change from an agent to a frustrative as in (5a and $5 b)$. When an agent, defined as [+VOL, +INST, -AFF], does not instigate anything, the subject argument changes. Since the +INST value does not hold, what we have is a frustrative-INST:

Feature changes under negation:

$\begin{array}{ll}\text { Agent } & \Rightarrow \text { Frustrative } \\ {[+\mathrm{VOL}][+\mathrm{INST}] \text { and }[-\mathrm{AFF}]} & \Rightarrow[+\mathrm{VOL}],[-\mathrm{INST}] \text { and }[-\mathrm{AFF}]\end{array}$




\section{Hypothetical Agent [+VOL, -INST, -AFF]}

This category has been created for the analysis of this study. Hypothetical agents can be interpreted as being +Volitional [+VOL], non Instigating or [-INST] and non Affected or $[-\mathrm{AFF}]$ and we find few cases of this category in our database $(5 \%)$. By hypothetical agent, we mean a participant that is volitionally involved in the event but does not instigate anything. In this sense, hypothetical agents deviate from the agent participants in that their capacity of instigation is of a hypothetical nature. In addition, frustratives and hypothetical agents have the same semantic features in common. The difference between them is that in the case frustratives the property of instigating is non-existent or absent, whereas for hypothetical agents, this property must be located in a hypothetical dimension.

The presence of certain operators at clause level (e.g. conditional sentences (if) explains the presence of hypothetical agents:

(6) a. If I suddenly stopped wearing a tie you might think it signified something - disrespect, dissatisfaction - and I'm not dissatisfied. Well, only with myself.». (THE 84)

b. As if he had just stopped running, his leaping, bursting heart slowly decelerated to its normal pace. (NONE 59)

The effects of some operators (e.g. mood, conditional sentences (if), or would/will) are very similar to those of negation, but they differ in the sense that they present an event as ocurring only hypothetically or under non-real circunstances; that is to say, an event conceived as not being instigated, or as having no effect on other participants. In consequence, they favour the presence of hypothetical agents and hypothetical experiences (as explained in the following paragraphs).

In the case of hypothetical agents, the operators act on the Instigating or INST feature. As the subject participant in these cases does not instigate an event, the resulting argument is a hypothetical agent. In other words, the starting point is an agent [+INST] that by not instigating an event becomes a hypothetical agent [-INST]:

Feature changes:

Agent $\Rightarrow$ Hypothetical Agent

$[+\mathrm{VOL}][+\mathbf{I N S T}]$ and $[-\mathrm{AFF}] \Rightarrow[+\mathrm{VOL}],[-\mathbf{I N S T}]$ and $[-\mathrm{AFF}]$

\section{Hypothetical Experiencer [+VOL], [-INST] and [-AFF]}

This category has also been created for the purpose of this study as the previous one has. By hypothetical experiencers we refer to participants which are +Volitional or [+VOL], non Instigating or [-INST] and non Affected or [-AFF] and show even a lower frequency then the previous category (2\%). Hypothetical experiencers are volitionally involved in the sense that their mental or sensory capacities are engaged in the event but their affectedness, (i.e. that of experiencing a sensory impression, or a mental or physical state) is situated in the future, or in an imagined or hypothetical dimension. 
As in the previous case, hypothetical experiencers can be justified in terms of certain operators at clause level (e.g. the use of conditional sentences or would/will):

(7) a. She is an intelligent woman, she'll enjoy sharing one of his old army quips, all his girls have heard it. - Don't ask to see the brigadier unless he sends for you. (PICK: 219)

b. There haven't been in his parents' house more than two two days when she says, if he feels like coming along, she feels quite happy to explore the village with him. (PICK 220)

In the case of hypothetical experiencers, these operators modify the affectedness or AFF feature from being Affected [+AFF] to being non Affected [-AFF]. That is to say, the effect of these operators result in a hypothetical experiencer:

Feature changes:

Experiencer $\quad \Rightarrow$ Hypothetical Experiencer

$[+\mathrm{VOL}],[-\mathrm{INST}]$ and $[+\mathbf{A F F}] \Rightarrow[+\mathrm{VOL}],[-\mathrm{INST}]$ and $[-\mathbf{A F F}]$

In conclusion, according to our corpus data, we have proved that the structure [subject] [main verb] [gerund] differs somewhat from the transitive event as far as the subject participant is concerned. On the one hand, the agent in these constructions does not correspond to the prototypical agent and, on the other hand, there is a greater range of other subject participants apart from the agent (i.e. experiencer, force, frustrative, hypothetical agent and hypothetical experiencer).

The following section is devoted to verbal semantics that is directly linked to the semantic properties of the participant types it subcategorises. We will analyse how participant types and verbal semantics correlate with each other and to what extent this correlation helps us to characterise the structure [subject] [main verb] [gerund].

\subsection{Verbal semantics}

A further issue to be discussed is how the previous participant types relate to the semantic properties of the verbs. From a descriptive point of view, the fact that a particular verb must be taken to always subcategorise for the same type of participants, comes from the assumption that there is an absolute correlation between a verbal lexeme and the semantic properties of its arguments. We have proved the existence of new types of participants as well operators functioning as «feature-switchers», therefore we believe that the best way to approach the correlation between a verbal lexeme and its arguments is to assume that verbs do not subcategorise for arguments, but rather for feature values.

To illustrate verbal subcategorisation, we will focus on three specific verbs of the first three main semantic categories, i.e. aspectual verbs (e.g. start), emotion verbs (e.g. enjoy) and cognitive perception verbs (e.g. imagine) with a frequency of $53 \%, 26 \%$ and $8 \%$ respectively. 
The verb start is compatible with the following participant types:

Agent [+VOL, +INST, -AFF]

(8) He says, »Come on, dance for me,» with her easy laugh, she says, »Why not? I'm generous that way,» and she starts moving smoothing her skin as though it's a rumpled dress. (HUM 212)

Hypothetical Agent [+VOL, -INST, -AFF]

(9) Soon the evening's audience would start arriving. She thought she might write notes for Elizabeth and Norah and leave them with the girls of the kitchen. (LOVE 246)

Frustrative [+VOL, -INST, -AFF]

(10) Nobody groped for words, nobody went silent, nor did anyone start jabbering a mile a minute. (HUM 197)

In short, Start subcategorises for [+VOL, -AFF] subjects which includes agents, hypothetical agents and frustratives participant types.

The verbs enjoy and imagine are compatible with the same participant types:

Experiencer [+VOL, -INST, +AFF]

(11)a. Although the Stark couple enjoyed breaking the law of segregation, from the comfort of their side, by coming at night into Chiawelo to listen to jazz recordings- Didymus was a collector and himself played the trumpet in those days!-and drink and perhaps dance, bumping into Sally's well-polished furniture. (NONE 62)

b. Sometimes he imagines a beautiful girl in a white dress wandering into the reading room and lingering distractedly after closing time; he imagines showing her over the mysteries of the bindery and cataloguing room, then emerging with her into the starry night. It never happens. (YOU 41)

Hypothetical Experiencer [+VOL, -INST, -AFF]:

(12) a. She is an intelligent woman, she'll enjoy sharing one of his old army quips, all his girls have heard it. - Don't ask to see the brigadier unless he sends for you. (PICK 219)

b. Imagine seeing the ill-concealed smirks and smiles of people at literary parties, as they whispered to each other over their glasses of white wine. (THIN 74)

Frustrative [+VOL, -INST, -AFF]:

(13) a. «It's a pity. Elizabeth would have enjoyed being a marchioness. Lady Elizabeth. He is extremely rich. Much richer than I am.» (LOVE 241)

b. The English were sensible people, after all, she had to agree to that. One 
couldn't imagine allowing battles between communists and fascists in the streets - well, there were some scuffles, but one mustn't exaggerate, there was nothing like Hitler. (SWEE 104)

In brief, Enjoy and Imagine subcategorise for [+VOL, -INST] subjects which include experiencers, hypothetical experiencers and frustratives.

On the whole, we can say that verbs in [subject] [main verb] [gerund] constructions mainly subcategorise for [+VOL, -AFF] and [+VOL, -INST] subjects which mainly include Agents and Experiencers (51\% and 29\% respectively).

\subsection{The object: the gerund}

As noted earlier, humanness and definiteness of arguments are considered as an integral part of the transitivity of events. The syntactic object, the gerund, in the structure [subject] [main verb] [gerund] does not correspond to the prototypical semantic patient because it is a non-human or non-highly definite entity recipient of the actions carried out or transferred in a transitive relationship and besides it is not typically concrete or visibly affected.

As a matter of fact, the gerund mainly codes actions, activities of motion and mental events according to the classifications proposed by Givón (2001), Delbecque (1987) and Faber and Mairal (1999). In this sense, before proceeding to illustrate the gerund encoding, it would be convenient to explain the term action according to Givón (2001). Actions must be understood as events deliberately initiated by an active agent and events imply a change from one state to another over a time and they can be construed as fast and bounded or slow and unbounded (Givón, 2001: 106)

Firstly, the gerund can code an action or activity (action verbs):

(14) a. He stopped fighting because of Steena. However mistaken he was about, he remained convinced that the mysterious forces that made their sexual ardor inexhaustible, ..., would one day work to dissolve his story of himself right before his eyes. (HUM 194)

b. «I'm having an affair with a thirty-four-year old woman. I can't tell you what it's done to me. Last night we had just finished dancing and she began to cry» (HUM 170)

In the second place, the gerund can also encode an activity of motion:

(15) a. He says, «Come on, dance for me,» with her easy laugh, she says, «Why not? I'm generous that way,» and she starts moving smoothing her skin as though it's a rumpled dress. (HUM 212)

b. «What happened to you ear?» «It is nothing,» he replies, and will not explain further. As they talk her gaze keeps drifting back to the misshapen ear. She would shudder, he is sure, if she had to touch it. (DISG 146) 
Finally, the gerund can evoke a mental event, through communication and cognitive perception verbs. These events are of a more abstract nature and require cognitive capacities (Givón, 2001):

(16)a. The two women began talking about the people they had gone to lunch with, in a hearty social way, and this became a joking exchange of gossip about neighbours, Joshua among them. (LOVE 245)

b. As I stopped thinking about her the campus came into focus, or as much as it can this morning with raindrops dribbling down the window panes streaking the dirt. (THIN 68)

In conclusion, the gerunds belonging to the categories of action and motion ( $42 \%$ and $12 \%$ respectively) evoke an event of a more concrete dimension, or in other words, they refer to concrete, real-world observable past or present events. Whereas the gerunds belonging to the categories of communication and cognitive perception verbs $(11 \%$ and $7 \%$ respectively) symbolize abstract events, occurring by means of words or thought (Verspoor, 2000).

Furthermore, this is directly related to Edelman's theory of consciousness (1989). In this context, the gerunds belonging to the categories of action and motion correspond to an event in the here and now, in a present or past frame of reference. In the case of gerunds belonging to the category of communication and cognitive perception verbs, they code the symbolic representation of spoken words and a mental image of an event respectively.

\subsection{General tendencies}

In section 3 we have corroborated that the structure [subject] [main verb] [gerund] does not correspond to the definition of transitive event in terms of prototypical agent and object. Firstly, in this structure the agent differs from the prototypical agent and besides this structure displays a greater variety of subject participants apart from the agent. Secondly, regarding the patient participant, the object of this structure does not correspond to the prototypical patient as it mainly evokes actions, activities of motion and mental events.

Taking into account all the elements discussed in section 3, we observe that the structure [subject] [main verb] [gerund] presents the following combinations among these elements:

\section{Linguistic realizations:}

a. [Subject] [Main verbs: Aspectual verbs]

[Gerund: action/motion/communication/cognitive perception verbs]

b. [Subject] [Main verbs: Emotion/Cognitive perception verbs] [Gerund: action/ motion verbs]

From a cognitive point of view, the structure [subject] [main verb] [gerund] differs from the semantic transitivity in the following terms. Semantic transitivity can be defined as a dynamic event whereby the patient is affected by an agent in a perceptible manner, whereas the structure [subject] [main verb] [gerund] implies a direct interaction between a subject and the object by means of some cognitive processes: 


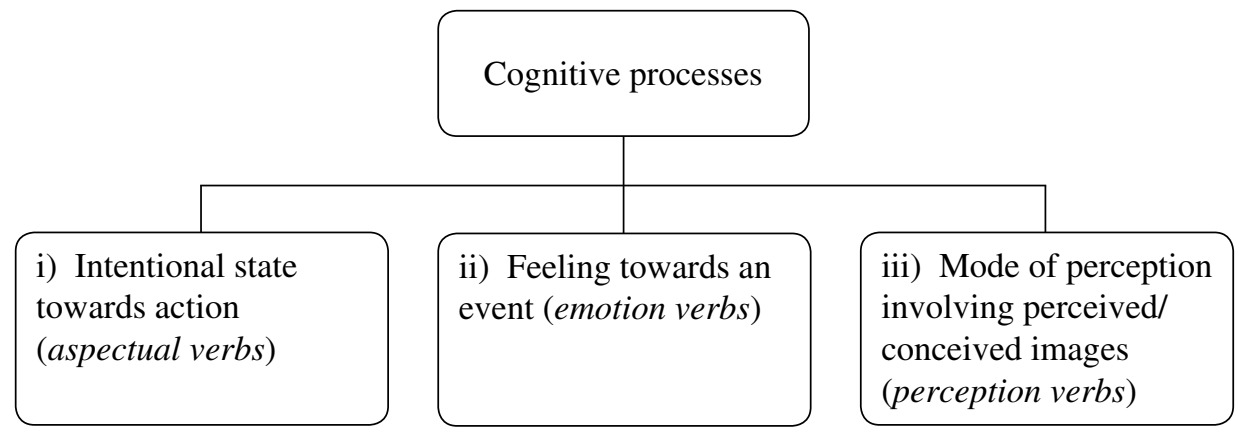

Figure (1): Cognitive processes involved in the structure [subject] [main verb] [gerund]

The cognitive processes by which this direct interaction occurs are: i) those denoting an intentional state towards action, ii) those denoting a feeling towards an event and iii) verbs denoting a mode of perception involving perceived or conceived images.

Cognitively speaking, the construal relations present in the structure [subject] [main verb] [gerund] are represented in the following Table (1):

Table (1): Construal relations in the structure [subject] [main verb] [gerund]

\begin{tabular}{|c|c|c|c|}
\hline Participants & Cognitive processes & \multicolumn{2}{|c|}{ Objects } \\
\hline \multirow{3}{*}{ Agent } & \multirow{3}{*}{$\begin{array}{l}\text { Intentional state } \\
\text { (begin, stop, go on) }\end{array}$} & Event & $\begin{array}{l}\text { Action\&motion } \\
\text { semantic type }\end{array}$ \\
\hline & & Symbol (words) & $\begin{array}{l}\text { Communication } \\
\text { semantic type }\end{array}$ \\
\hline & & $\begin{array}{l}\text { Mental image of an } \\
\text { event }\end{array}$ & $\begin{array}{l}\text { Cognitive perception } \\
\text { semantic type }\end{array}$ \\
\hline \multirow[t]{2}{*}{ Experiencer } & $\begin{array}{l}\text { Feeling } \\
\text { (enjoy, suffer, feel like) }\end{array}$ & \multirow{2}{*}{ Event } & \multirow{2}{*}{$\begin{array}{l}\text { Action\&motion } \\
\text { semantic type }\end{array}$} \\
\hline & $\begin{array}{l}\text { Mode of perception } \\
\text { (imagine, recollect, ) }\end{array}$ & & \\
\hline
\end{tabular}

There are two construal relations involved in the structure [subject] [main verb] [gerund] that can be summarised in the following terms. In the first place, an agent interacts directly with an event, a symbol representing words and a mental image of an event by means of the cognitive process consisting of an intentional state. Secondly, an experiencer interacts directly with an event through the cognitive processes of feeling and perception.

\section{Conclusions}

We have proved that a characterisation of the structure [subject] [main verb] [gerund] can be done by taking as a reference some of the semantic features of Prototypical Transitivity.

The subject participant in this structure does not correspond to the prototypical agent. There are two elements which explain this: firstly, the subject participant of these 
constructions is not involved in a dynamic event and, secondly, there are other participant types apart from the agent (i.e. experiencer, force, frustrative, hypothetical agent and hypothetical experiencer).

There are grammatical operators at clause level (e.g. negation, conditional sentences, etc.) that explain some of the previous participant types (i.e. frustrative, hypothetical agent and hypothetical experiencer). This confirms, in turn, the importance of studying these constructions at clause level.

We have also proved that the correlation between a verbal lexeme and its arguments is based on the assumption that verbs do not subcategorise for arguments, but rather for feature values. The fact that main verbs in these constructions mainly subcategorise for [+VOL, $-\mathrm{AFF}]$ and [+VOL, -INST] subjects confirms, on the one hand, that these constructions are not prototypical and, on the other, that they have a greater variety of participant types.

The object, the gerund, does not conform to the prototypical patient because it is a non-human or non-highly definite entity and is not visibly affected. In fact, it generally evokes actions, activities of motion and mental events. This is closely linked to Edelman's theory of consciousness (1989), in the sense that the gerunds belonging to the categories of action and motion make reference to events in the here and now. Whereas the gerunds belonging to the category of communication and cognitive perception category refer to the symbolic representation of spoken words and a mental image of an event respectively.

In contrast with semantic transitivity, we can assert that the structure [subject] [main verb] [gerund] entails a direct interaction between a subject and the object (i.e. an event, a symbol representing words and a mental image), through some cognitive processes (i.e. an intentional state, a feeling and a mode of perception towards an event).

\section{Notes}

1. My corpus is an English-Spanish parallel corpus compiled specifically for my $\mathrm{PhD}$. It consists of approximately 2000 items. For this study, I have only focused on the English data (more specifically just on 250 items). The title of the source texts and their specific codes are the following:

\begin{tabular}{|c|c|c|c|}
\hline Author & Genre & Publication & Original Text \\
\hline D. Lodge & Novel & $\begin{array}{l}2002 \\
2001\end{array}$ & $\begin{array}{l}\text { Thinks }(=\mathrm{THIN}) \\
\text { Therapy }(=\mathrm{THE})\end{array}$ \\
\hline D. Lessing & Novel & $\begin{array}{l}1996 \\
2006\end{array}$ & $\begin{array}{l}\text { Love, again }(=\mathrm{LOVE}) \\
\text { The sweetest dream (=SWEE) }\end{array}$ \\
\hline N. Gordimer & Novel & $\begin{array}{l}1995 \\
2005\end{array}$ & $\begin{array}{l}\text { None to accompany me (=NONE) } \\
\text { The pickup (=PICK) }\end{array}$ \\
\hline J. M. Coetzee & Novel & $\begin{array}{l}2004 \\
2000\end{array}$ & $\begin{array}{l}\text { Youth (=YOU) } \\
\text { Disgrace (=DISG) }\end{array}$ \\
\hline J. Updike & Novel & $\begin{array}{l}1998 \\
2003\end{array}$ & $\begin{array}{l}\text { In the beauty of the lilies (= LILIE) } \\
\text { Licks of love (=RAB) }\end{array}$ \\
\hline R. Philip & Novel & $\begin{array}{l}1997 \\
2001\end{array}$ & $\begin{array}{l}\text { Sabbath's theatre }(=\mathrm{SAB}) \\
\text { The human stain }(=\mathrm{HUM})\end{array}$ \\
\hline
\end{tabular}




\section{REFERENCES}

Comrie, B. (1973). The ergative: Variations on a theme. Lingua 32.239-53.

Croft, W. (1990). Typology and Universals. Cambridge University Press.

Croft, W. \& D. A. Cruse (2004). Cognitive Linguistics. Cambridge University Press.

Cruse, D. A. (1973). Some thoughts on agentivity. Journal of Linguistics 9(1): 11-23.

DeLancey, S. (1984). Notes on agentivity and causation. Studies in Language 8, 181-213.

DelbecQue, N. (1987). Problèmes et méthodes de l'étude de la variation syntaxique: le cas de la position du sujet en espagnol. Leuven: Universitaire Pers.

Dik, S. (1997). Functional grammar. Amsterdam: North-Holland.

Edelman, G. M. (1989). The Remembered Present: A Biological Theory of Consciousness. New York: Basic Books Inc.

Faber, P. \& R. Mairal. (1999). Constructing a lexicon of English verbs. Berlin: Mouton de Gruyter.

Givón, T. (1980). The binding hierarchy and the typology of complements. Studies in Language 4, 3, 333-377.

- (2001). Syntax. Vol. I. Amsterdam: John Benjamins.

Hopper, P. J. \& S. A. Thompson. (1980). Transitivity in Grammar and Discourse. Language 56: 251-299.

- (1995). The category «event» in natural discourse and logic. In: Abraham, W., Givón, T., Thompson, S. A. (Eds.), Discourse Grammar and Typology. John Benjamins Publishing Company, Amsterdam/Philadelphia, 139-150.

Kemmer, S. (1993). The middle voice. Amsterdam: Benjamins.

KitTILÄ, S. (2002). Remarks on the basic transitive sentence. Language Sciences 24(2): 107-130.

- (2006). The anomaly of the verb «give» explained by its high (fornal and semantic) transitivity. Linguistics 44(3): 569-612.

Langacker, R. W. (2000). Grammar and Conceptualization. Berlin - New York: Mouton de Gruyter.

- (2008). Cognitive grammar: a basic introduction. Oxford: Oxford University Press.

MoravcsiK, E. (1978). On the distribution of ergative and accusative patterns. Lingua 45. 233-79.

NAess, Å. (2007). Prototypical transitivity. Amsterdam: John Benjamins.

Palmer, F. R., (1994). Grammatical Roles and Relations. Cambridge University Press.

Radden, G. \& R. DiRven. (2007). Cognitive English Grammar. Amsterdam: John Benjamins.

TsunODA. T. (1985). Remarks on transitivity. Journal of Linguistics 21, 385-396.

VersPoor, M. (1996). «The story of -ing: A subjective perspective». In: Pütz, M. \& R. Dirven (Eds.), The construal of Space in Language and Thought, 417-454.

- (2000). «Iconicity in English complement constructions: conceptual distance and cognitive processing levels». In: Horie, K. (Ed.), Complementation, Amsterdam-Philadelphia: John Benjamins, 199-225. 